European Association for the Development of Renewable Energies,

Environment and Power Quality
International Conference on Renewable Energies and Power Quality (ICREPQ’09)

Valencia (Spain), 15th to 17th April, 2009

\title{
Harmonics in Power Systems
}

\author{
J.L. Hernández ${ }^{1}$, MA. Castro ${ }^{2}$, J. Carpio ${ }^{2}$ and A. Colmenar ${ }^{2}$ \\ ${ }^{1}$ Department of Electricity. IES La Laboral de La Laguna. \\ Avda. Lora y Tamayo, 2. La Laguna. Tenerife. \\ Phone/Fax number: 34922251140/34922251144 e-mail: juanluis@tuveras.com \\ ${ }^{2}$ Department of Electrical, Electronic and Control Engineering \\ E.T.S.I.I.- U.N.E.D. \\ C. Juan del Rosal, 12. Ciudad Universitaria. Madrid 28040. Spain. \\ Phone/Fax number: 34 913986480/34 913986028, e-mail: acolmenar@ieec.uned
}

\begin{abstract}
We present a set of three posters to give an overview of "The harmonics in power systems", with a synthesis study on three aspects: generalities".

Poster 1: "Harmonics in power systems:

Poster 2: "Harmonics in power systems: power".

Poster 3: "Harmonics in power systems: effects, solutions, standards”.
\end{abstract}

\section{Keywords}

Harmonics, pollution, IEEE, Budeanu, distortion, effects, solutions.

\section{Introduction}

The increase in recent years of loads of electronic components has created a major change in the characteristics of electrical installations, which are evident when analyzing the waveforms of voltage and current in those circuits, which are increasingly different from pure sinusoidal signals, due to various disturbances, one of them are the harmonics. The contents covered in this paper is structured into three posters, size A0, as it is explained below.

\section{Poster 1: "Harmonics in power systems: generalities”.}

- General characteristics of the harmonics, measure of the distortion of the wave, harmonic impedances. Decomposition of a harmonic distorted signal.

- Nonlinear loads as the source of harmonics. Propagation of harmonics in the network. Influence of phase angle of harmonics

- Sequence, direct, inverse and homopolar, the harmonics in a balanced three-phase system.

The details are shown in figures 1 and 2.

\section{Poster 2: "Harmonics in power systems: power"}

- Theories to the study of single-phase electric power systems in the presence of harmonics: [Budeanu], [IEEE].

- Theories to the study of three-phase electric power systems, balanced and unbalanced, with the presence of harmonics: [Budeanu], [IEEE].

The details are shown in figures 3 and 4.

\section{Poster 3: "Harmonics in power systems: effects, solutions, standards"}

- Effects of harmonics in the different components of an electrical system.

- Techniques to reduce harmonics.

- Reference and standards

The details are shown in figures 5, 6 and 7. 


\section{Detail of posters}

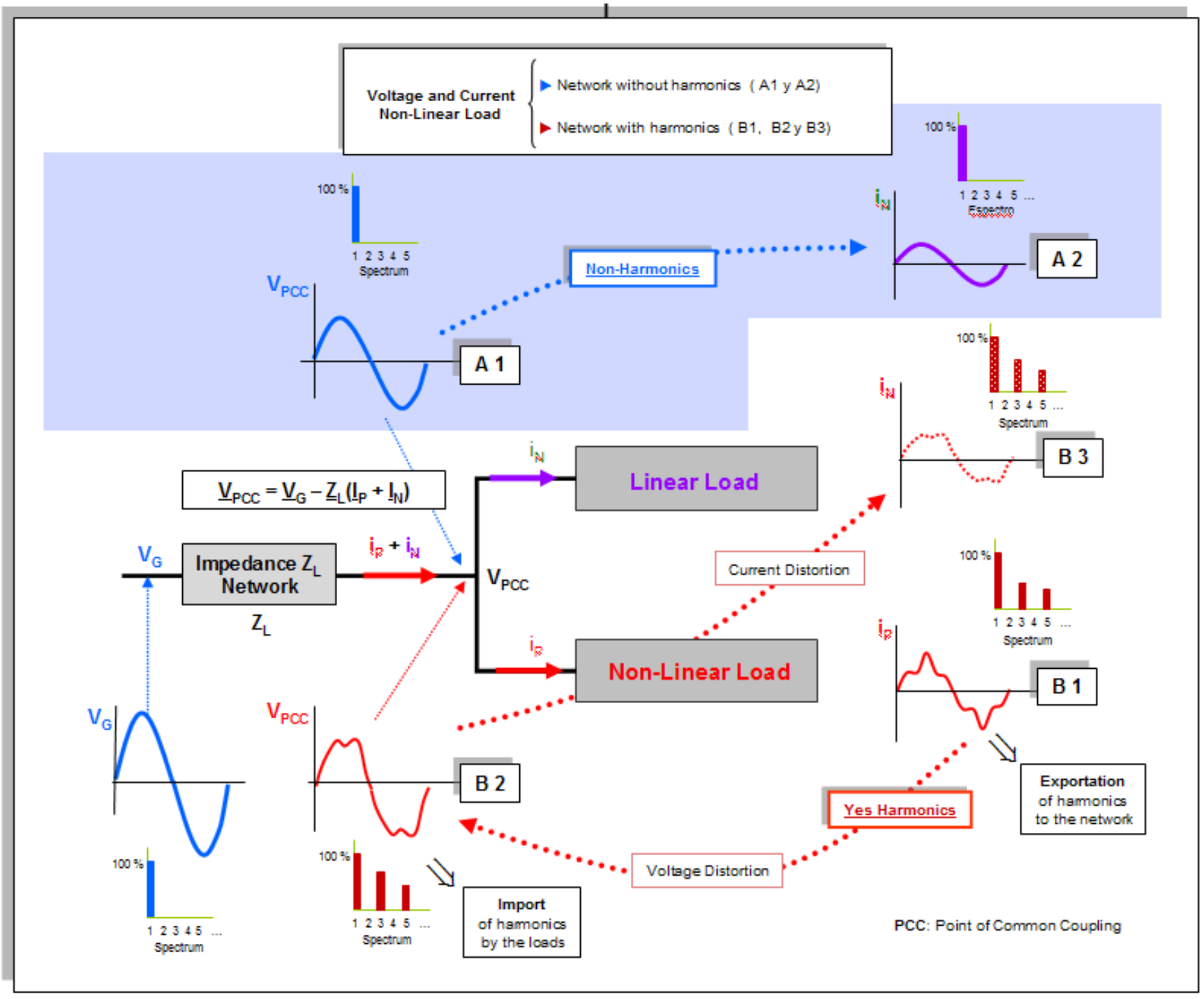

Fig. 1. Detail of poster 1.
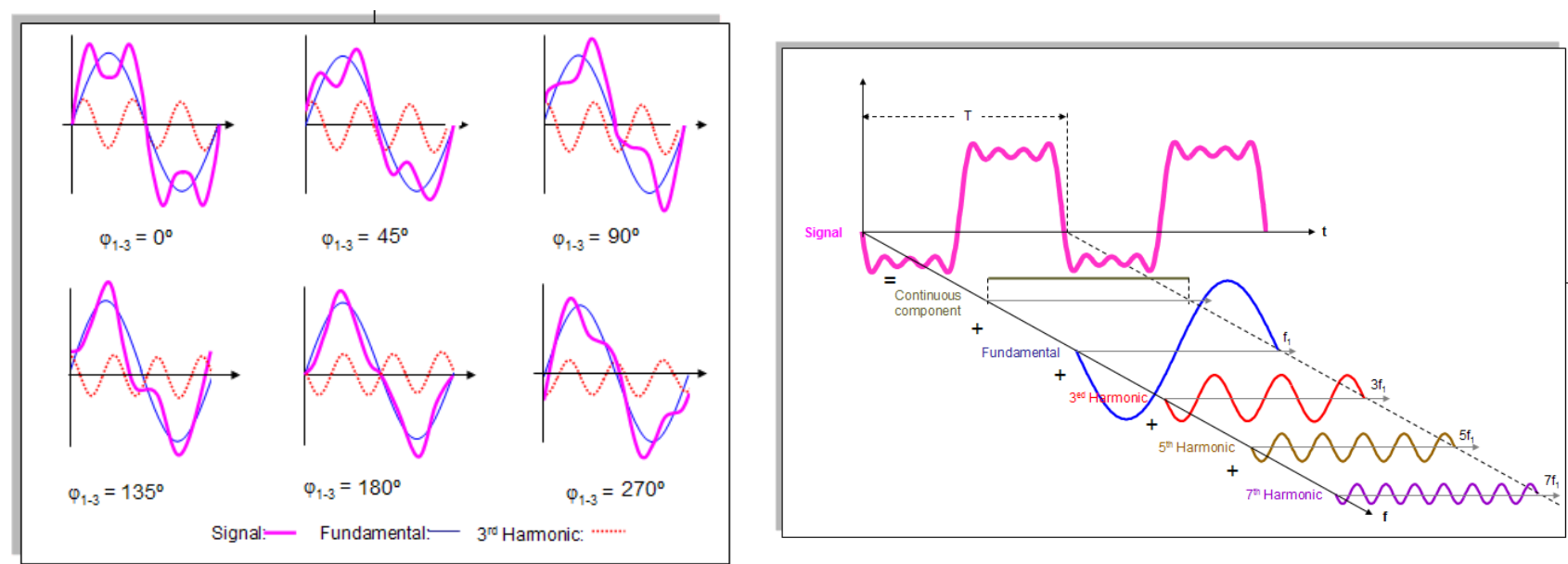

Fig. 2. Detail of poster 1 . 


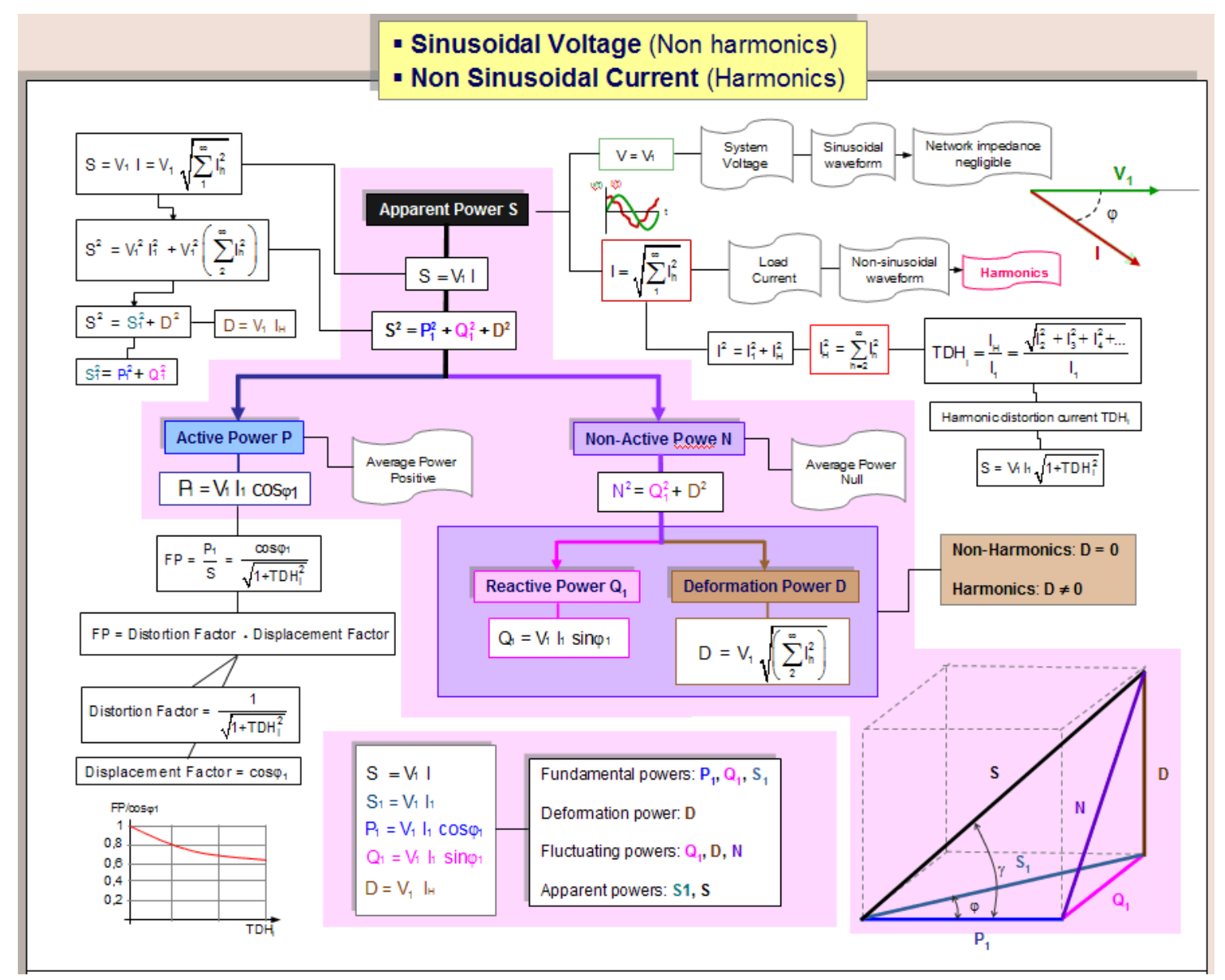

Fig. 3. Detail of poster 2.

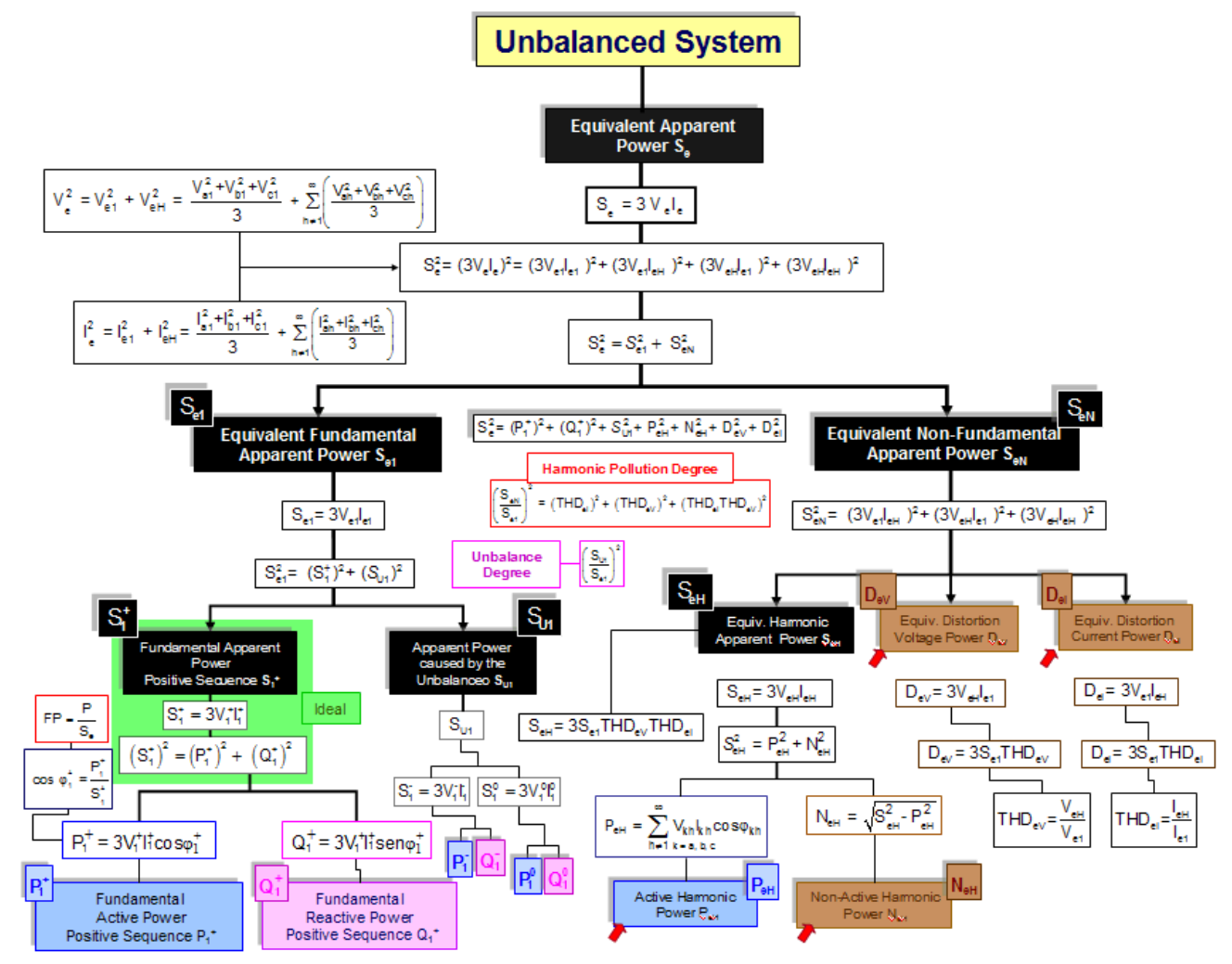

Fig. 4. Detail of poster 2. 


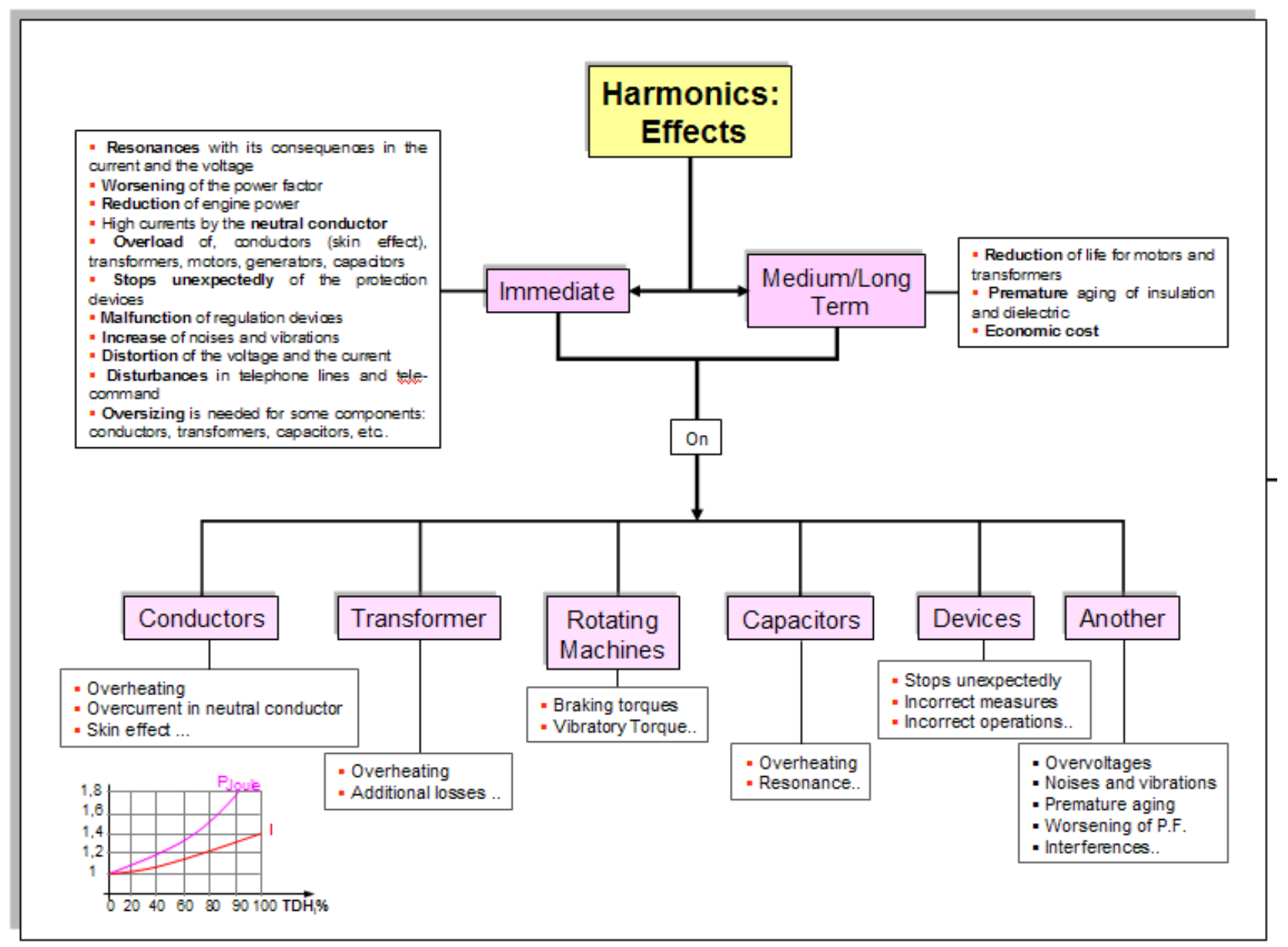

Fig. 5. Detail of poster 3.

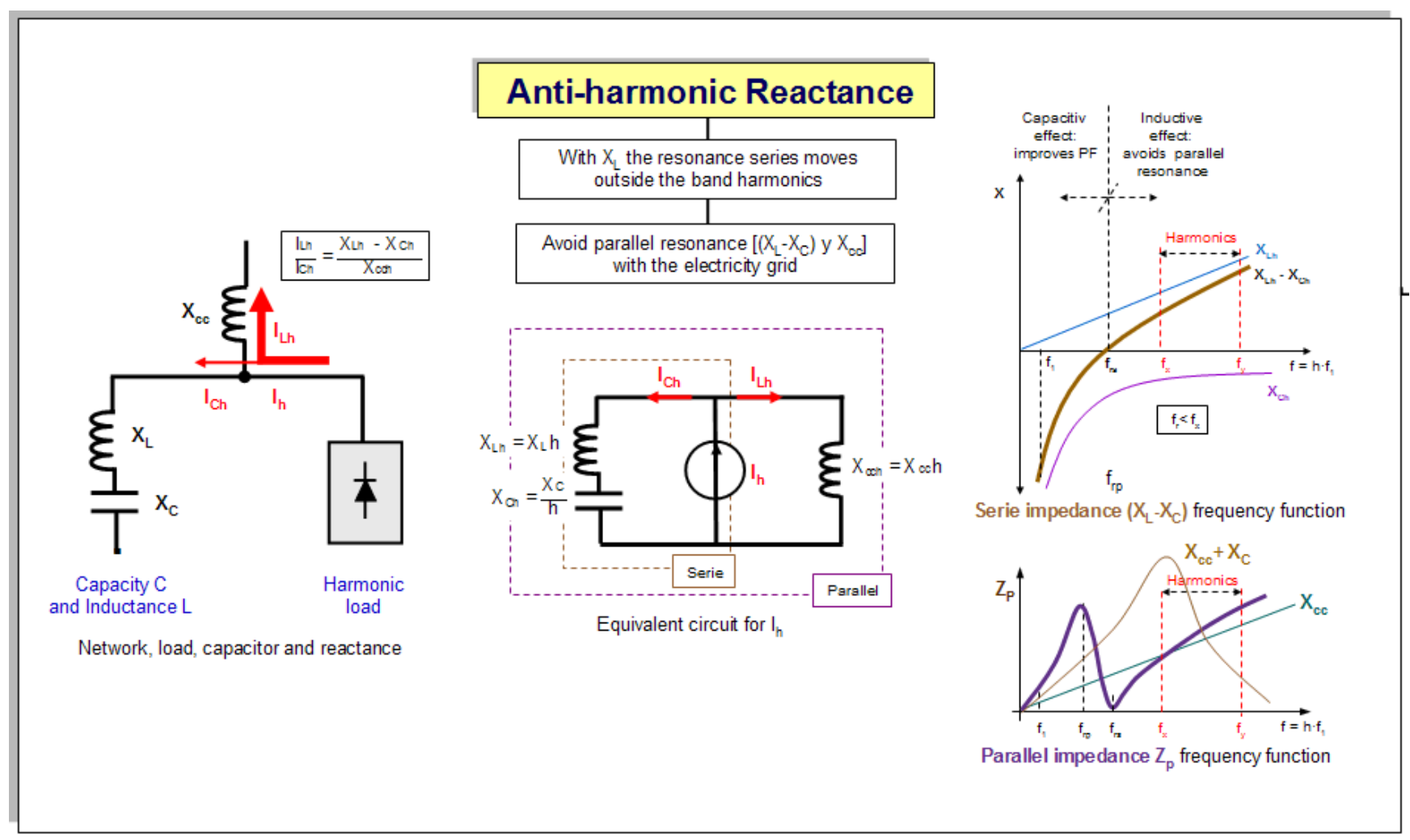

Fig. 6. Detail of poster 3. 


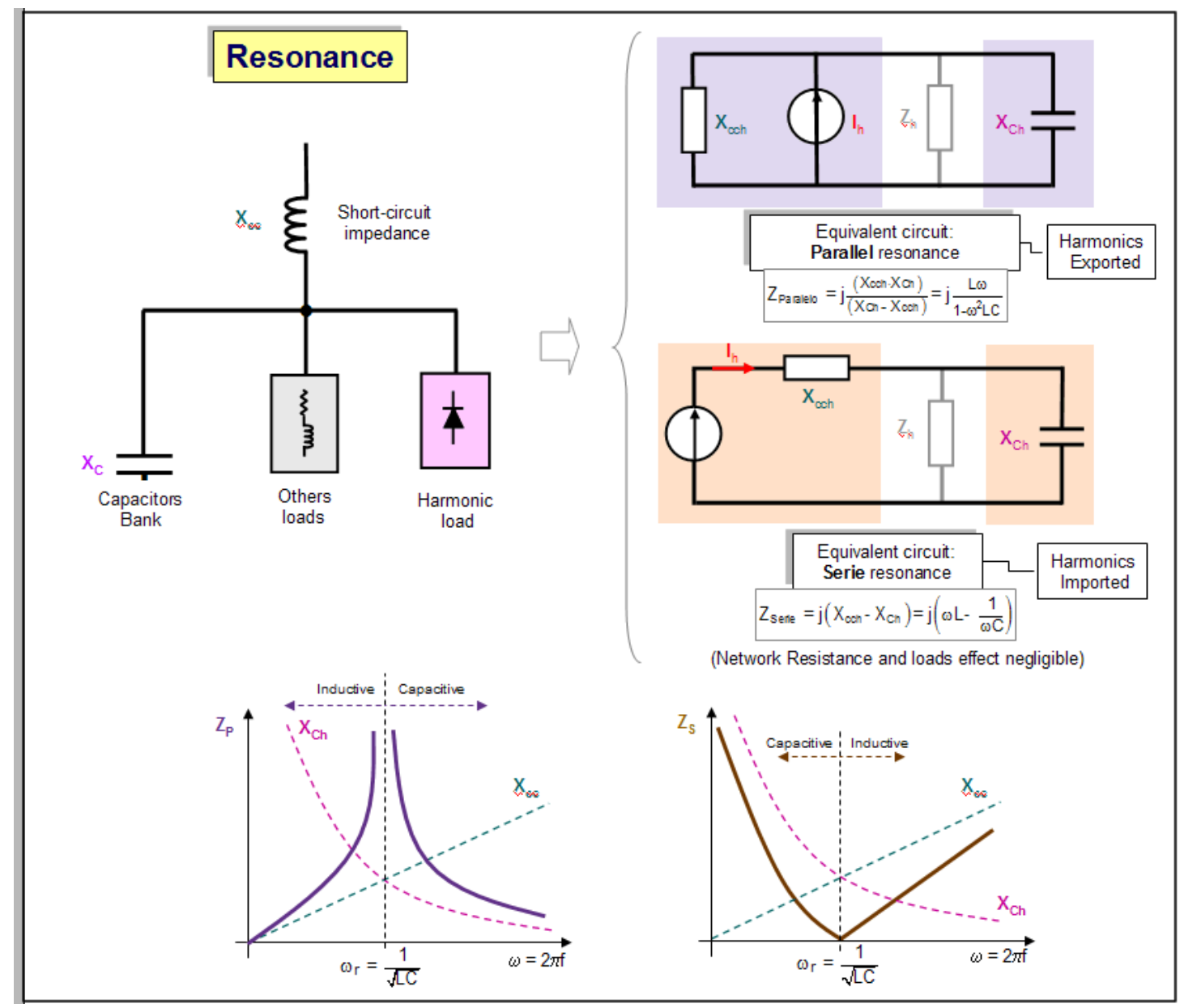

Fig. 7. Detail of poster 3.

\section{Conclusion}

Harmonics have harmful effects in: conductors, electrical machines, different types of electrical devices, billing, etc. Therefore, at present, it is very important to consider their presence in the design and maintenance of electrical installations.

\section{References}

[1] A.E. Emanuel, "Apparent and reactive power in three phases systems in search of physical meaning and a better resolution', ETEP-Eur. Trans. Elect. Power Eng., Vol. 3, No 1, pp: 7-14, Jan. /Feb. 1993.

[2] A.E Emanuel, "Apparent Power Definitions for Three-Phase Systems,” IEEE Transactions on Power Delivery, Vol. 14, No. 3, pp. 767-772, July 1999.

[3] IEEE Working Group on Nonsinusoidal Situations, "Practical Definitions for Powers in Systems with Nonsinusoidal Waveforms and Unbalanced Loads," IEEE Transactions on Power Delivery, Vol. 11, No. 1, pp.79-101, Jan. 1996.
[4] P. Filipski and R. Arseneau, "Definition and measurement of apparent power under distorted waveform conditions', IEEE Tutorial cours on non sinusoidal situations, pp.37-42, 90 EH0327-7.1990.

[5] E. H. Watanabe, R. M. Stephan, Member and M. Aredes "New Concepts Of Instantaneous Actjye And Reactive Powers In Electrical Systems With Generic Loads”. IEEE Transactions on Power Delivery, Vol. 8, No. 2, pp 697-703, April 1993.

[6] M.A.E. Alali, “'Contribution à l'Etude des Compensateurs Actifs des Réseaux Electriques Basse Tension”, Thèse de doctorat, l'Université Louis Pasteur, Strasbourg, September 2002.

[7] L. I. Eguíluz, "Facturación de la electricidad: calidad y eficiencia”. Seminario Nuevo Marco Energético, Universidad Internacional Menéndez y Pelayo, Santander, July 2003.

[8] F. Redondo, "La energía reactiva y la disminución de las pérdidas en distribución de energía eléctrica”, revista Energía, No 4, 1998, pp. 91-96.

[9] http://www.leonardo-energy.org/power-quality-communitypractice/. Accesed on January 2009.

[10] http://www.tuveras.com/ Accesed on January 2009. 